\title{
Impact of a climate network: The role of intermediaries in local level climate action
}

\author{
Santtu Karhinen ${ }^{\text {a }}$, Juha Peltomaa ${ }^{\mathrm{b}}$, Venla Riekkinen ${ }^{\mathrm{b}}$, Laura Saikku ${ }^{\mathrm{b}, *}$ \\ ${ }^{a}$ Finnish Environment Institute, Oulu, Finland \\ ${ }^{\mathrm{b}}$ Finnish Environment Institute, Helsinki, Finland
}

\section{A R T I C L E I N F O}

\section{Keywords:}

Intermediaries

Climate

Mitigation

Network

Emissions

\begin{abstract}
A B S T R A C T
Local governments have set highly ambitious greenhouse gas emission reduction targets on a strategic level, in some cases influenced by intermediary networks. Yet, the quantitative impacts of climate strategies or the sharing of best practices on emissions still remain largely unknown. The aim of this study was to examine the impact of an intermediary network on municipal greenhouse gas emissions. This was done through an econometric analysis of the emissions of municipalities that are members of the Finnish Hinku (Towards Carbon Neutral Municipalities) network, and through comprehensive qualitative interviews conducted in 40 of those municipalities. Our quantitative results show that Hinku network membership has successfully led to the lowering of greenhouse gas emission levels in participating municipalities. The qualitative interviews suggest that this is due to systematic local level climate work, enhanced by network membership. The network functions as an intermediary in two ways: by providing expertise and enabling peer-support. In addition, it has also succeeded in legitimising local level climate action. Ambitious local level climate action can also affect the ambition of national climate policy, which in turn may reflect on the amount resources allocated to local climate action.
\end{abstract}

\section{Introduction}

The European Union and its member countries aim to be climate neutral by 2050. A few countries are aiming for the same target well before then. Alongside national and supranational targets and measures, local governments have set their own emission reduction targets, which can be even more ambitious than national ones, as is the case in the Nordic countries (Seppälä et al., 2019). Local governments also play a major role in putting targets into practice. Local governments manage infrastructure, control city planning and may influence the actions of their residents and companies.

Yet, without coordination between different climate actors, it is unlikely that local governments will deliver on their potential to close the emissions gap (Nagorny-Koring, 2018; Boehnke et al., 2019; Palermo et al., 2020). Municipal climate networks can be seen as facilitating forms of global climate governance that enable local governments to adopt climate policies independently and proactively. Membership of these intermediary networks has indeed proven to increase climate action (Rashidi and Patt, 2018; Gordon and Johnson, 2018; Fuhr et al., 2018; Heikkinen et al., 2019).
In practice, intermediary networks can aggregate knowledge and foster learning horizontally across different contexts (e.g. geographical spaces, governmental branches or cultures), or function vertically in offering support, help to build capacities and connect different levels of governance (Matschoss and Heiskanen, 2017; Kivimaa et al., 2019; Gustafsson and Mignon, 2020). However, the positive effect of increased climate measures, for instance, is dependent on several factors, such as how tailored the solutions offered by the network are (Rashidi and Patt, 2018). Furthermore, establishing a direct link between municipal targets, subsequent climate action and eventually, achieved emission reductions has been difficult (Millard-Ball, 2012; Damsø et al., 2017; Reckien et al., 2018).

Econometric methods can be used to investigate the key drivers of greenhouse gas (GHG) emission levels in municipalities. Previous statistical studies that have investigated the issue have mostly been on a national scale (see e.g. Dogan and Seker, 2016; Dong et al., 2019; Eskander and Fankhauser, 2020). A few regional level studies exist, focusing mostly on China (see e.g. Zhou and Liu, 2016; Huang et al., 2019). Recently there has been increasing interest in analyzing the emission reductions of transnational climate networks (Hsu et al., 2020).

\footnotetext{
* Corresponding author at: Finnish Environment Institute, Latokartanonkaari 11, 00790 Helsinki, Finland

E-mail address: laura.saikku@syke.fi (L. Saikku).
} 
Yet, there has been no quantitative knowledge on the impact of climate networks on emissions at the municipal level within a single country (Hoppe et al., 2016; Boehnke et al., 2019).

All existing quantitative studies have analysed emission determinants using econometric methods. However, there are no studies using an econometric approach in estimating the importance of different factors such as climate network membership or local climate action on municipal greenhouse gas emissions. The closest reference is the study by Hsu et al. (2020), where the emission reductions of over 1000 Covenant of Mayors cities were investigated. The study focuses on identifying the factors that determine if a city is on track to achieving its emission reduction target. Thus, they do not specifically investigate whether joining a climate network has an added impact on emission reductions.

The reason for scarce literature examining the determinants of municipal greenhouse gas emissions is mostly due to the lack of municipal greenhouse gas inventories, which fortunately are available in Finland. An additional advantage of the dataset is that the calculation is conducted using the same methodology for all municipalities. As pointed out by Hsu et al. (2020), the differences in calculation principles can make comparability difficult in the international context. In this study we were able to circumvent this issue.

One example of a national climate network is the Finnish Towards Carbon Neutral Municipalities (Hinku) network, which was chosen as a case study for this article. The network is facilitated by a national research institute and consists of municipalities committed to ambitious emission reduction targets. There are previous indications of the success of this particular network in raising climate ambition and strategic thinking on the local level (Matschoss and Heiskanen, 2017; Lukkarinen et al., 2018). However, like other climate networks, its impacts on municipal greenhouse gas emissions have thus far been difficult to assess. To address this gap, we analysed the impacts of the Hinku network on emissions, posing two research questions:

\section{- What are the measured impacts of climate network membership on emissions? \\ - How does network membership affect local climate work and members' efforts to reach their emission reduction targets?}

Two complementary approaches were used to address these questions. First, we performed a statistical analysis with econometric methods on the connection between regional emission levels and Hinku membership. Secondly, we conducted 40 qualitative interviews with the Hinku municipalities in order to assess the potential factors behind network membership affecting municipal climate work.

This article is organized as follows. The case study, materials and methods are described in Section 2. Results of both the quantitative and qualitative research are presented in Section 3. Section 4 discusses the key findings in relation to the role of intermediary networks in reducing local level climate emissions and provides policy implications. Section 5 concludes the article.

\section{Materials and methods}

\subsection{Case Hinku - Towards carbon neutral municipalities}

Hinku is a network of Finnish municipalities committed to achieving an $80 \%$ reduction in their greenhouse gas emissions from 2007 levels by 2030. Municipal members agree to this target by decision of the municipal council upon joining. The network is coordinated by the Finnish Environment Institute (SYKE), which functions under the jurisdiction of the Ministry of the Environment. The network has a steering group consisting of its members along with relevant key stakeholders, such as the Association of Finnish Municipalities. Municipality is the form of self-governing local authority in Finland, from small towns to large cities. 107 of Finland's 310 municipalities also hold a city status
(Association of Finnish Municipalities, 2019).

To pursue the emission reduction target, a set of criteria have been established for member municipalities. These include appointing a contact person and establishing a climate working group, where key municipal administrative units are represented. The working group's task is to devise an annual climate action plan, implement necessary investments and report on the progress of the municipality's climate activities both internally and externally. The municipality should also join the Energy Efficiency Agreement for Municipal Sector (EEAM). The purpose of the criteria is to ensure cross-sectoral and systemic climate work in the member municipalities.

Hinku started as a project consisting of five small municipalities in 2008 and has since grown rapidly. For our study, we chose to include member municipalities that had joined the network by the end of 2018 . This was done to ensure that the municipalities, interviewed in 2019, had at least some experience of the functioning of the network. At end of 2018, the network included 44 municipalities with over 782000 inhabitants (approximately $14.2 \%$ of the Finnish population in 2018). At the time of the statistical analyses, however, annual municipal emissions data was only available from 2005 to 2017 . As such, there is a slight difference in the number of Hinku municipalities included in statistical (37) and qualitative (40) analyses.

\subsection{Statistical analysis}

\subsubsection{Municipal greenhouse gas emissions}

The statistical analysis was based on detailed local level greenhouse gas emission data, that has recently been calculated for all Finnish municipalities ( $\mathrm{N}=310$ ) for the years 2005-2017 (for detailed calculation principles, see Lounasheimo et al., 2020a, 2020b). The calculation model (called ALas) follows the principles of the basic level of the Global Protocol for Community-Scale Greenhouse Gas Emission Inventories, the GPC (GHG Protocol, 2014). In contrast to the GPC basic level, the ALas model includes agriculture, F-gases and grid losses, but excludes local air traffic. A total of 80 emission sectors are included in the open database (Lounasheimo et al., 2020c). Due to the lack of localised data, the calculation excludes air traffic, foreign boat traffic, ice breakers, industrial processes and the land use, land use change and forestry (LULUCF) sector. For example, in 2017 the missing emissions (excl. LULUCF) were $4700 \mathrm{kt} \mathrm{CO2-eq.,} \mathrm{which} \mathrm{corresponds} \mathrm{to} 8.5 \%$ of all emissions reported in the national greenhouse gas inventory. The calculation is mainly production-based but the emissions of some sectors, such as district heating and electricity usage, are calculated based on consumption.

The ALas model was developed to support climate work carried out by municipalities. The default reporting option is the so-called Hinku calculation, which includes emissions that municipalities can influence directly or indirectly through their actions. The Hinku calculation excludes emissions related to industrial electricity consumption, fuel usage of industrial plants regulated under the EU Emissions Trading System (ETS), industrial waste treatment as well as through traffic of trucks, vans and buses. The Hinku calculation also includes the possibility to attribute added emission reductions from wind power generation in favour of the municipality via an emission compensation mechanism. However, in this study we left out this compensation mechanism, as we wanted to focus on the actual amounts of emissions generated in each municipality.

Generally, emissions had decreased in 292 and increased in 18 of the 310 Finnish municipalities during the studied period of 2005-2017. Emissions from oil heating, electricity consumption and waste treatment had decreased in almost every municipality (see Fig. 1). For example, in nearly all municipalities emission reductions related to electricity usage are partly due to the decreasing emissions of electricity generation in the Finnish power system (Finnish Energy, 2020). On the other hand, there were large differences in e.g. district heating, agriculture and traffic emissions between municipalities. 


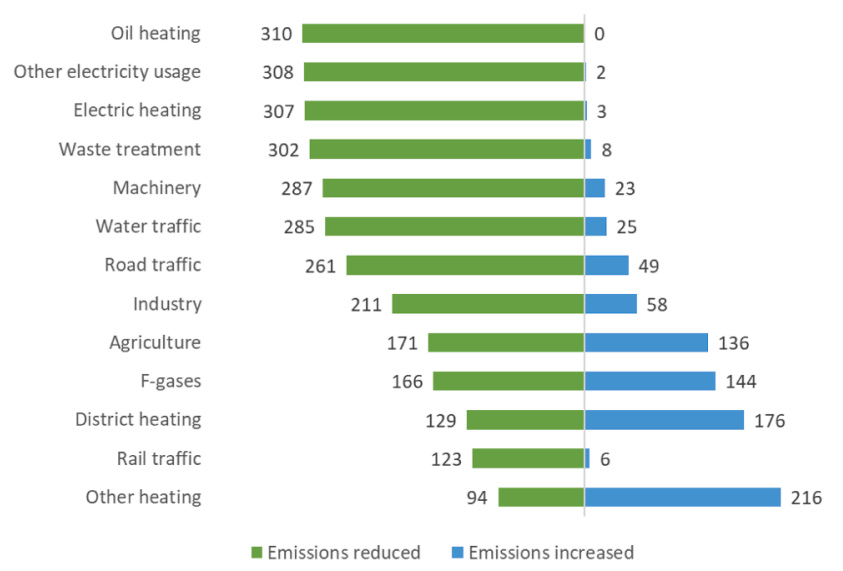

Fig. 1. Number of municipalities where sector-specific emissions have either reduced (on the left) or increased (on the right) between 2005 and 2017.

\subsubsection{Data and methodology}

As our main hypothesis we proposed that the levels of municipalities' greenhouse gas emissions would be lower after becoming a member of the Hinku network. The econometric analysis included all 37 municipalities that had joined the network before 2018. The Hinku indicator variable was formulated as:

$H_{i n k} u_{i t}=\left\{\begin{array}{l}1=\text { municipality } i \text { belongs to the Hinku network in year } t \\ 0=\text { municipality } i \text { does not belong to the Hinku network in year } t\end{array}\right.$

Factors that exogenously (i.e. out of the municipality's direct control) determine the level of greenhouse gas emissions needed to be controlled to identify the impact of Hinku on municipalities' emissions. In this study, we included control variables related to four main classes: i) weather conditions, ii) sociodemographic characteristics of the population, iii) regional characteristics and iv) regional economy and fuel market prices.

Weather conditions include the average temperature in a year and the sum of yearly precipitation. Weather variables are measured as the averages of grid points in the weather model by the Finnish Meteorological Institute (Aalto et al., 2016). Especially temperature was expected to have a significant effect on the amount of emissions as a large share $(27 \%)$ of Finnish energy consumption is related to the heating of buildings (OSF, 2020a).

Population is described by the number of inhabitants, average disposable income, the share of persons with higher education (bachelor's, master's or doctoral degree) and the shares of employees commuting to or from the municipality. Previous literature has shown that higher income (Minx et al., 2013; Dogan and Seker, 2016) and a larger population (Liu et al., 2015; Zhou and Liu, 2016) result in higher greenhouse gas emissions. Furthermore, Franzen and Vogl (2013) showed that there is a relationship between higher education and environmental consciousness.

Shares of different urban zones (7 categories in the urban zone classification), average occupancy rates, shares of political parties in city councils, and participation in the Energy Efficiency Agreement for Municipal Sector (EEAM) represent the impacts of regional characteristics on emissions. For example, Wiedenhofer et al. (2017) have shown that urban form plays a role in greenhouse gas generation, but its impact may be case-specific (see e.g. Ottelin et al., 2019; Salo et al., 2019). Spacious household occupancy was expected to increase emissions as, for example, more heating per capita is required. Occupancy rate may be influenced by the municipality's policymakers, but these changes tend to be very slow due to capital being bound in the existing building stock. As our sample period covers only thirteen years, we treated occupancy rate as an exogenous control factor in our analysis.

Political party composition in the city council was included to control for the impact of overall environmental consciousness on municipal emissions (see e.g. Garmann, 2014). There is a clear distinction between parties that are considered more pro-environment (Green League and Left Alliance) and parties which are more conservative (Finns Party, Swedish People's Party, Centre Party, Social Democratic Party, National Coalition Party and Christian Democrats). Lastly, participation in the Energy Efficiency Agreement for Municipal Sector (EEAM) was used to control for other pro-environmental attitudes that are not necessarily related to Hinku.

Regional economic characteristics included in the modelling were the annual contribution margin per capita, shares of employees in industrial or service sectors, regional gross domestic product and the market prices for hard coal, peat and electricity. Instead of gross domestic product (as used, for example, in Hsu et al., 2020), we propose that the annual contribution margin of a municipality is a better shortterm proxy for describing resource availability for climate work execution. Annual contribution margin represents the income financing that is available for investments and the paying of loan instalments after running costs have been covered. It is considered as a key figure when evaluating the adequacy of a municipality's income financing. A negative annual contribution margin per capita, for example, would indicate that the income financing is too low to even cover running costs, even if the region's GDP were high. Instead, GDP better describes the level of infrastructure accumulated over a longer term (e.g. road infrastructure and access to services) that enables more cost-efficient actions to reduce emissions. A higher service sector share was expected to indicate lower emissions, as the combined share of primary production and industry would consequently be lower (see e.g. Zhang and Lin, 2012; Wang and Liu, 2017). Regional GDP is measured on a slightly less detailed level (LAU 1 in the Local Administrative Unit regional classification). There are 70 LAU 1 regions in Finland.

The usage of fossil fuels is a key determinant of emissions. However, we chose not to include fossil fuel consumption levels directly in the estimation, as Hinku membership might alter their usage. For instance, district heat producers are commonly owned by municipalities, giving them some control over fuel choice. The direct inclusion of coal and oil consumption in the estimation might absorb part of the emission impact of Hinku membership. On the other hand, price levels of coal and peat were included in the estimation to capture any market-driven changes (not related to climate work) in coal and peat consumption levels. Higher prices of coal and peat could decrease their usage (whenever possible, from a technological point-of-view) in municipalities dependent on them, which should lower municipal emissions. Coal and peat prices are chosen to represent global and regional fuel price developments. We do not include oil price as its variation is highly correlated with coal price. Similarly, we leave out the price of wood chips as its price development correlates with peat price.

Descriptive statistics of the variables used in the regression modelling are provided in Table 1. Data on population characteristics was collected from the population structure (OSF, 2020b), employment (OSF, 2020c) and income distribution (OSF, 2020d) statistics. Municipal characteristics are from the population structure (OSF, 2020b), dwellings and housing condition (OSF, 2020e) and municipal elections OSF (2020f) statistics. Localised economic data was collected from local government finances (OSF, 2020g) and regional accounts (OSF, 2020h). Fuel and electricity prices are from energy price statistics (OSF, 2020i).

An empirical two-way fixed effects panel data regression model was used to estimate the influence of Hinku membership on municipalities' emissions. A random effects model was also considered, but the Hausman (1978) specification test showed that a fixed effects model should be applied. We took a natural logarithm of the dependent variable to linearize the relationship with explanatory variables, to make the error distribution more normally distributed and to ease the interpretation of results. The empirical model is written as:

$\ln E_{i t}=\alpha_{i}+H i n k u_{i t} \delta+\mathbf{x}_{i t}^{\prime} \beta+\varepsilon_{i t}$, 
Table 1

Descriptive statistics of the variables in regression analysis. Hypotheses reflect the expected signs of the regression coefficients based on previous literature.

\begin{tabular}{|c|c|c|c|c|c|}
\hline Variable & Min & Max & Mean & $\begin{array}{l}\text { St. } \\
\text { dev. }\end{array}$ & Hypothesis \\
\hline Emissions, total $\left(\mathrm{kt} \mathrm{CO}_{2} \mathrm{e}\right)$ & 8.0 & 3737.7 & 148.2 & 265.3 & dependent \\
\hline $\begin{array}{l}\text { Emissions per capita }(\mathrm{t} \\
\left.\mathrm{CO}_{2} \mathrm{e}\right)\end{array}$ & 3.2 & 34.3 & 11.7 & 4.4 & dependent \\
\hline $\begin{array}{l}\text { Average temperature } \\
\text { (Celsius) }\end{array}$ & -2.7 & 8.3 & 4.4 & 1.6 & - \\
\hline $\begin{array}{l}\text { Precipitation (millimetres } \\
\text { per year) }\end{array}$ & 375.1 & 1031.9 & 643.1 & 99.5 & \pm \\
\hline \multirow{2}{*}{$\begin{array}{l}\text { Population (number of } \\
\text { persons) }\end{array}$} & \multirow[t]{2}{*}{734} & 643 & 18 & \multirow[t]{2}{*}{46} & \multirow[t]{2}{*}{+} \\
\hline & & 272 & 248 & & \\
\hline $\begin{array}{l}\text { Disposable income } \\
\text { (thousand euros) }\end{array}$ & 13.8 & 67.8 & 23.4 & 4.4 & + \\
\hline $\begin{array}{l}\text { Share of persons with high } \\
\text { education (\%) }\end{array}$ & 2.5 & 38.6 & 9.4 & 4.1 & - \\
\hline $\begin{array}{l}\text { Share of employees } \\
\text { commuting in (\%) }\end{array}$ & 7.7 & 70.1 & 28.6 & 11.8 & + \\
\hline $\begin{array}{l}\text { Share of employees } \\
\text { commuting out (\%) }\end{array}$ & 6.8 & 80.7 & 37.4 & 17.9 & - \\
\hline $\begin{array}{l}\text { Share of K1 (Inner urban } \\
\text { area) }(\%)\end{array}$ & 0.0 & 93.4 & 5.1 & 14.6 & - \\
\hline $\begin{array}{l}\text { Share of K2 (Outer urban } \\
\text { area) (\%) }\end{array}$ & 0.0 & 97.6 & 9.5 & 20.8 & - \\
\hline $\begin{array}{l}\text { Share of K3 (Peri-urban } \\
\text { area) }(\%)\end{array}$ & 0.0 & 98.5 & 9.9 & 22.0 & - \\
\hline $\begin{array}{l}\text { Share of M4 (Local centers } \\
\text { in rural areas)(\%) }\end{array}$ & 0.0 & 89.8 & 7.7 & 20.4 & - \\
\hline $\begin{array}{l}\text { Share of M5 (Rural areas } \\
\text { close to urban areas) (\%) }\end{array}$ & 0.0 & 99.4 & 11.7 & 23.4 & - \\
\hline $\begin{array}{l}\text { Share of M6 (Rural } \\
\text { heartland areas) (\%) }\end{array}$ & 0.0 & 100.0 & 32.0 & 38.6 & - \\
\hline $\begin{array}{l}\text { Share of M7 (Sparsely } \\
\text { populated rural areas) } \\
(\%)\end{array}$ & 0.0 & 100.0 & 23.4 & 36.3 & reference \\
\hline $\begin{array}{l}\text { Occupancy rate }\left(\mathrm{m}^{2} \text { per }\right. \\
\text { capita) }\end{array}$ & 31.2 & 52.1 & 42.2 & 3.3 & + \\
\hline GDP per capita $(€)$ & 14463 & 59844 & 30181 & 7801 & + \\
\hline $\begin{array}{l}\text { Share of empl. in primary } \\
\text { production (\%) }\end{array}$ & 0.1 & 55.3 & 13.2 & 9.1 & reference \\
\hline $\begin{array}{l}\text { Share of empl. in } \\
\text { industrial sector (\%) }\end{array}$ & 2.0 & 67.8 & 25.0 & 10.1 & + \\
\hline $\begin{array}{l}\text { Share of empl. in service } \\
\text { sector (\%) }\end{array}$ & 23.8 & 97.1 & 61.8 & 10.5 & - \\
\hline $\begin{array}{l}\text { Share of National } \\
\text { Coalition Party (\%) }\end{array}$ & 0.0 & 52.6 & 16.7 & 10.4 & \pm \\
\hline $\begin{array}{l}\text { Share of Social Democratic } \\
\text { Party (\%) }\end{array}$ & 0.0 & 51.2 & 18.2 & 10.3 & \pm \\
\hline Share of Centre Party (\%) & 0.0 & 94.1 & 37.6 & 20.4 & reference \\
\hline Share of Green League (\%) & 0.0 & 33.3 & 2.6 & 4.1 & - \\
\hline Share of Finns Party (\%) & 0.0 & 40.7 & 6.9 & 7.3 & \pm \\
\hline Share of Left Alliance (\%) & 0.0 & 37.2 & 7.2 & 7.6 & \pm \\
\hline $\begin{array}{l}\text { Share of Swedish People's } \\
\text { Party (\%) }\end{array}$ & 0.0 & 100.0 & 4.7 & 15.7 & \pm \\
\hline $\begin{array}{l}\text { Share of Christian } \\
\text { Democrats }(\%)\end{array}$ & 0.0 & 76.9 & 3.3 & 5.1 & \pm \\
\hline $\begin{array}{l}\text { Annual contribution } \\
\text { margin per capita }(€)\end{array}$ & -1319 & 4682 & 313 & 279 & - \\
\hline Coal price (euros/MWh) & 13.5 & 39.3 & 24.2 & 8.4 & - \\
\hline Peat price (euros/MWh) & 9.5 & 20.6 & 14.5 & 3.9 & - \\
\hline $\begin{array}{l}\text { Electricity (energy) price } \\
\text { (euros/MWh) }\end{array}$ & 29.7 & 56.6 & 39.4 & 8.7 & \pm \\
\hline
\end{tabular}

where $i \in\{1, \cdots, 310\}$ are municipalities, $t=(2005, \cdots, 2017)$ are years in the sample period, $E_{i t}$ are emissions of municipality $i$ in year $t, \alpha_{i}$ are the municipality-specific fixed effects, $\mathbf{x}_{i t}$ includes the control variables, and error term $\varepsilon_{i t}$ is independent and identically distributed over municipalities $i$ and years $t$. We are mostly concerned with the coefficient of the Hinku indicator $\delta$, which is, due to logarithmic transformation, interpreted directly as a percentage change in emissions due to joining the Hinku network. To account for any remaining non-linearities in the model the population size, disposable income, shares of industrial and service sector employees and fuel prices were transformed into natural logarithms. A Maddala-Wu (Maddala and Wu, 1999) unit root test showed that all variables are stationary at $1 \%$ risk level. As additional checks, we estimated additional models explaining sectoral emissions from Lounasheimo et al. (2020c), whole effort sharing sector emissions and per capita emissions.

\subsection{Qualitative methodology}

The representatives of all Hinku municipalities that had joined the network by the end of 2018 were interviewed, with the exceptions of four municipalities - two due to personnel changes and two for other reasons. A total of 40 interviews were conducted in the latter part of 2019. Of the interviewed municipalities, 11 were classed as urban and 29 as rural (OSF, 2020b). Most interviewed municipalities were small to medium in size, with an average population of around 18300 , ranging from 1852 to 84403 (OSF, 2020b). Over half of the municipalities had $<10000$ inhabitants and only four over 50000 . On average municipalities had been a member of the Hinku network for 5 years at the time of the interview, ranging from little under a year to almost 12 years. The interviewed municipalities are somewhat representative of Finland's municipalities overall, $18 \%$ of which are classed as urban, with an overall average population of around 17800.

30 interviews were conducted individually and 10 in pairs or groups of three. The interviews were conducted both in person and online by researchers of SYKE, and their average duration was 73 min (ranging from 36 to $126 \mathrm{~min}$ ). From each municipality, the Hinku contact person and/or another member of staff involved with their climate work was interviewed. Almost two thirds of the interviews included a person or people who had worked with Hinku matters since the municipality joined the network. However, several interviewees had only been involved for one or two years.

In the semi-structured interviews, participants were first asked about their role in the municipality's climate activities. After this, questions covered how the Hinku network may have affected the organisation of climate work in the municipalities. Participants were then asked about past and upcoming concrete emission reduction measures triggered by the network, with estimations of the their impactfulness, finishing with questions relating to the municipalities' broader roles (see Table 2). The one to two-hour interviews were recorded and transcribed. They were then analysed using content analytical methods, by categorizing responses in relation to how the network has affected climate action in the

Table 2

Thematic topics of the interviews and questions' relevance within the research framework.

\begin{tabular}{|c|c|}
\hline Thematic topics of the interviews & $\begin{array}{l}\text { Questions' relevance within research } \\
\text { framework }\end{array}$ \\
\hline $\begin{array}{l}\text { 1. The role of Hinku in the } \\
\text { municipality's climate activities }\end{array}$ & $\begin{array}{l}\text { Understanding motivations for joining the } \\
\text { Hinku-network, the support expected and } \\
\text { received from it and the perceived } \\
\text { usefulness of the network. Finding sharing } \\
\text { of good mitigation practices and } \\
\text { communication between other Hinku- } \\
\text { municipalities }\end{array}$ \\
\hline $\begin{array}{l}\text { 2. The effect of Hinku membership on } \\
\text { the organisation of climate work in } \\
\text { the municipalities }\end{array}$ & $\begin{array}{l}\text { Understanding the organisation of climate } \\
\text { work within the municipal organisation in } \\
\text { relation to the Hinku-criteria, and the } \\
\text { communication with and engagement of } \\
\text { other municipal and external actors of the } \\
\text { municipality in implementing climate } \\
\text { work }\end{array}$ \\
\hline $\begin{array}{l}\text { 3. Concrete climate change mitigation } \\
\text { actions implemented in the } \\
\text { municipality }\end{array}$ & $\begin{array}{l}\text { Understanding the range of concrete } \\
\text { actions implemented in the } \\
\text { municipalities, their motivations, and the } \\
\text { perceived impact of the network on } \\
\text { emission reductions }\end{array}$ \\
\hline $\begin{array}{l}\text { 4. The role of the municipality in } \\
\text { implementing national climate policy }\end{array}$ & $\begin{array}{l}\text { Understanding the experiences and } \\
\text { perceptions of municipalities' roles as } \\
\text { forerunners }\end{array}$ \\
\hline
\end{tabular}


municipalities. The approach combined conventional and directed content analysis in deriving relevant categories from the data but being simultaneously guided by a prior understanding of the different functions an intermediary network fulfils (Hsieh and Shannon, 2005).

Table 3

Regression results of municipal greenhouse gas emissions in 2005-2017.

\begin{tabular}{|c|c|c|c|c|}
\hline \multicolumn{5}{|c|}{ Dependent variable: Natural logarithm of greenhouse gas emissions (kt $\mathrm{CO}_{2}$-eq.) } \\
\hline & Model 1 & Model 2 & Model 3 & Model 4 \\
\hline \multirow[t]{2}{*}{ Hinku } & $-0.120^{* * *}$ & $-0.045^{* * *}$ & $-0.046^{* * *}$ & $-0.031^{* * *}$ \\
\hline & $(0.016)$ & $(0.013)$ & $(0.013)$ & $(0.012)$ \\
\hline \multirow[t]{2}{*}{ EEAM } & $-0.088^{* * *}$ & $-0.011^{*}$ & $-0.011^{*}$ & 0.001 \\
\hline & $(0.007)$ & $(0.006)$ & $(0.006)$ & $(0.006)$ \\
\hline \multirow[t]{2}{*}{ Temperature } & $-0.043^{* * *}$ & $-0.034 * * *$ & $-0.035^{* * *}$ & $-0.017^{* * *}$ \\
\hline & $(0.001)$ & $(0.001)$ & $(0.001)$ & $(0.001)$ \\
\hline \multirow[t]{2}{*}{ Precipitation } & $-0.00003^{* *}$ & $-0.00004^{* * *}$ & $-0.00004 * * *$ & $0.0001^{* * *}$ \\
\hline & $(0.00001)$ & $(0.00001)$ & $(0.00001)$ & $(0.00001)$ \\
\hline \multirow[t]{2}{*}{$\ln$ (Population size) } & & $0.656^{* * *}$ & $0.529 * * *$ & $0.538^{* * *}$ \\
\hline & & $(0.063)$ & $(0.105)$ & $(0.100)$ \\
\hline \multirow[t]{2}{*}{$\ln$ (Disposable income) } & & $0.312^{* * *}$ & $0.371 * * *$ & $0.379 * * *$ \\
\hline & & $(0.051)$ & $(0.049)$ & $(0.059)$ \\
\hline \multirow[t]{2}{*}{ Share of higher education } & & $-0.060^{* * *}$ & $-0.056^{* * *}$ & $-0.029^{* * *}$ \\
\hline & & $(0.004)$ & $(0.005)$ & $(0.005)$ \\
\hline \multirow[t]{2}{*}{ Share of commuting in } & & & -0.0004 & 0.001 \\
\hline & & & $(0.001)$ & $(0.001)$ \\
\hline \multirow[t]{2}{*}{ Share of commuting out } & & & $-0.003^{* * *}$ & $-0.002^{*}$ \\
\hline & & & $(0.001)$ & $(0.001)$ \\
\hline \multirow[t]{2}{*}{ Share of K1 } & & & -0.006 & -0.011 \\
\hline & & & $(0.016)$ & $(0.015)$ \\
\hline \multirow[t]{2}{*}{ Share of K2 } & & & -0.015 & -0.020 \\
\hline & & & $(0.014)$ & $(0.012)$ \\
\hline \multirow[t]{2}{*}{ Share of K3 } & & & 0.0004 & -0.008 \\
\hline & & & $(0.009)$ & $(0.008)$ \\
\hline Share of M4 & & & -0.011 & -0.010 \\
\hline & & & $(0.011)$ & $(0.009)$ \\
\hline Share of M5 & & & 0.0001 & -0.006 \\
\hline & & & $(0.007)$ & $(0.007)$ \\
\hline Share of M6 & & & -0.011 & -0.014 \\
\hline & & & $(0.009)$ & $(0.009)$ \\
\hline Occupancy rate & & & -0.004 & $0.011^{* *}$ \\
\hline & & & $(0.005)$ & $(0.004)$ \\
\hline Annual contribution margin & & & & $-0.009^{*}$ \\
\hline & & & & $(0.005)$ \\
\hline GDP per capita & & & & $0.009^{* * *}$ \\
\hline & & & & $(3.245 \mathrm{e}-03)$ \\
\hline$(\text { GDP per capita })^{2}$ & & & & $-0.0001^{* * *}$ \\
\hline & & & & $(4.314 \mathrm{e}-05)$ \\
\hline $\ln$ (Industrial employment) & & & & 0.013 \\
\hline & & & & $(0.018)$ \\
\hline $\ln$ (Service employment) & & & & $-0.120^{* * *}$ \\
\hline & & & & $(0.040)$ \\
\hline National Coalition Party & & & & 0.0004 \\
\hline & & & & $(0.0005)$ \\
\hline Social Democratic Party & & & & 0.001 \\
\hline & & & & $(0.001)$ \\
\hline Green League & & & & $-0.002^{* *}$ \\
\hline & & & & $(0.001)$ \\
\hline Finns Party & & & & $-0.001^{* *}$ \\
\hline & & & & $(0.001)$ \\
\hline Left Alliance & & & & -0.001 \\
\hline & & & & $(0.001)$ \\
\hline Swedish People's Party & & & & $0.002 * * *$ \\
\hline & & & & $(0.0004)$ \\
\hline Christian Democrats & & & & 0.0003 \\
\hline & & & & $(0.001)$ \\
\hline $\ln ($ Coal price) & & & & $-0.128^{* * *}$ \\
\hline & & & & $(0.008)$ \\
\hline $\ln$ (Peat price) & & & & $-0.064 * * *$ \\
\hline & & & & $(0.016)$ \\
\hline $\ln$ (Electricity price) & & & & $0.111^{* * *}$ \\
\hline & & & & $(0.004)$ \\
\hline Number of observations & 3822 & 3822 & 3822 & 3822 \\
\hline Adjusted $\mathrm{R}^{2}$ & 0.199 & 0.588 & 0.593 & 0.689 \\
\hline F statistics & $312.204 * * *(\mathrm{df}=4 ; 3524)$ & $822.097^{* * *}(\mathrm{df}=7 ; 3521)$ & $367.267^{* * *}(\mathrm{df}=16 ; 3512)$ & $284.107^{* * *}(\mathrm{df}=31 ; 3497)$ \\
\hline
\end{tabular}

Notes: Clustered standard errors are shown in parentheses. Reference categories are the share of M7, the share of primary production and the share of Centre Party. * $\mathrm{p}$ $<0.1 ; * * \mathrm{p}<0.05 ; * * \mathrm{p}<0.01$ 


\section{Results}

\subsection{Statistical analysis}

The regression results show a statistically highly significant negative relationship between Hinku network membership (the Hinku indicator) and municipalities' greenhouse gas emissions (Table 3 ). That is, the emissions of Hinku municipalities during 2005-2017 were $3.1( \pm 2.3) \%$ lower than they would have been without joining to the Hinku network (shown in Model 4). The estimates with 95\% confidence intervals are shown in Fig. 2. The results were constructed sequentially by adding variables to Model 1, which included only weather conditions, Hinku and EEAM indicators. The explanatory power of Model 1 was relatively low with an adjusted $\mathrm{R}^{2}$ of 0.2 . Model 4 is the most detailed form with all control variables. The $\mathrm{R}^{2}$ of Model 4 increased to 0.69 , which is a reasonably good model fit. The highest increase in the explanatory power was achieved when including the population characteristics.

Alongside the relationship between Hinku membership and

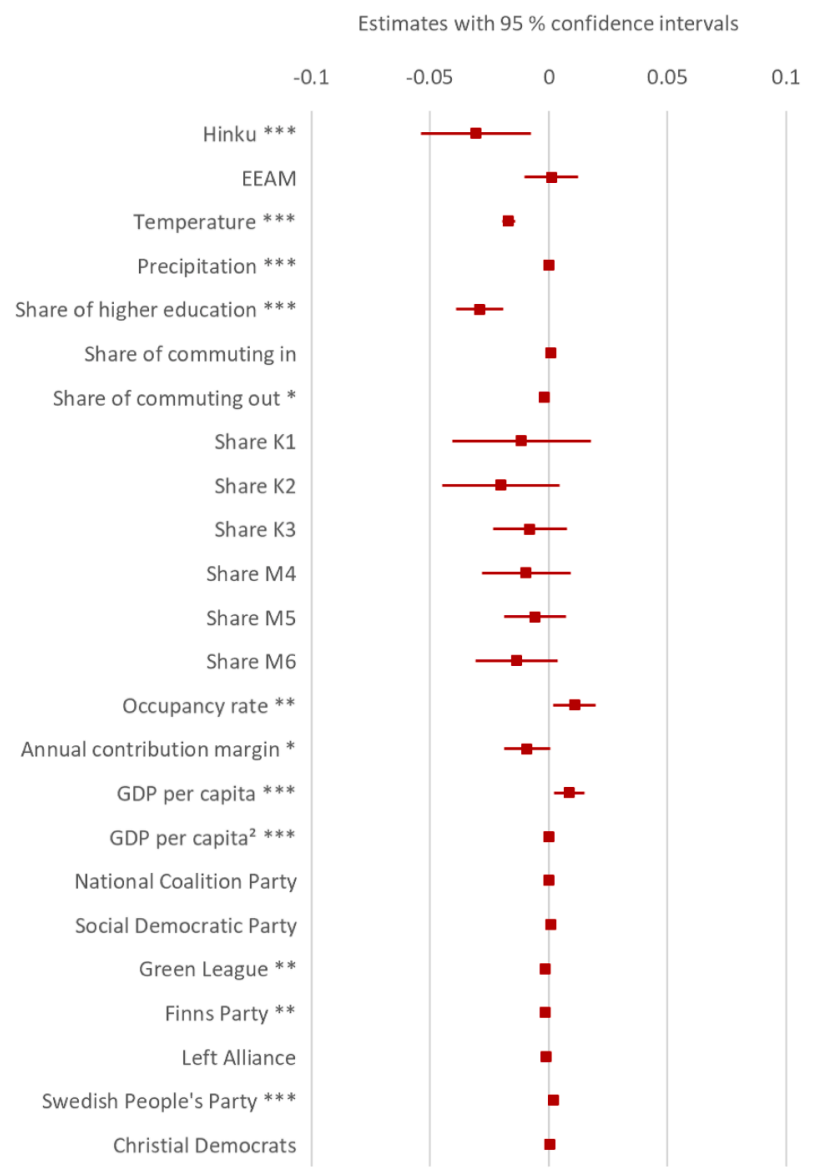

Estimates with $95 \%$ confidence intervals

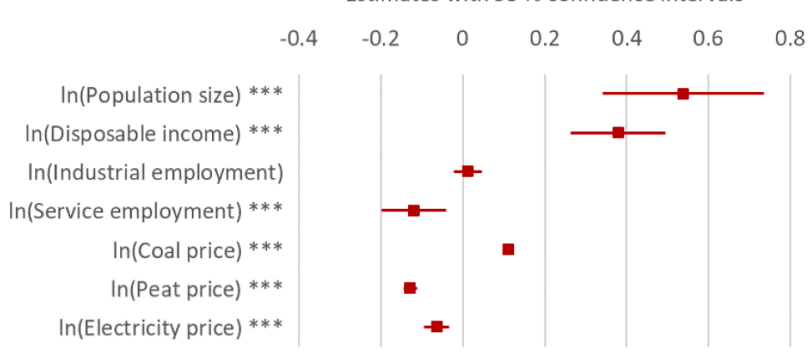

Fig. 2. Estimates of Model 4 with confidence intervals. ${ }^{*} \mathrm{p}<0.1$; ${ }^{* *} \mathrm{p}<0.05$; $* * * \mathrm{p}<0.01$. greenhouse gas emissions, the analysis provides other meaningful and interesting results. As expected, the coefficient of temperature is statistically highly significant and has a negative sign. On average, greenhouse gas emissions decrease by $1.7 \%$ as annual average temperature is 1 Celsius degree higher. Municipalities with higher population size and higher average disposable income have higher total emissions. Furthermore, a larger share of highly educated people is associated with lower emission levels. More spacious living conditions increase emissions, as expected. Participation in the Energy Efficiency Agreement does not lower emissions statistically significantly.

Based on our results, urban form does not play any role in emissions generation. The insignificance of urban form is interesting, as it has been shown to have an effect on emissions, at least when consumer carbon footprints are considered (Ala-Mantila et al., 2014). Our results differ from this branch of literature in that our focus is on territorial greenhouse gas emissions, which differs from life-cycle analysis related to consumption patterns. Still, it is interesting why urban form plays no role in determining municipal greenhouse gas emissions. To further analyse the relation between urban form and emissions, we performed a stepwise analysis (Appendix A). In Model A1 we included Hinku and EEAM indicators, weather conditions and shares of different urban rural classes. Our results show that urban form is crucial in explaining emissions when nothing else is controlled for. On the other hand, when population size and average disposable income (describing job situation) are included in the estimation (Models A2 and A3), urban form no longer plays a role in explaining emissions.

Interestingly, a better economic position of a municipality, measured in annual contribution margin per capita, has a statistically significant decreasing effect on emissions. This result has important implications for national policymaking when designing municipalities' income financing. Otherwise, results seem intuitive: a higher service sector share, higher fuel prices and higher Green League representation in the city council result in lower emissions. On the other hand, slightly counterintuitive is the negative coefficient of the Finns Party, as the party is known for its climate sceptic attitudes.

Estimation results in Table 3 considered the total municipal emissions. To examine how Hinku membership has affected sector-specific and per capita emissions, we conducted additional regression analyses with the same specification than Model 4 in Table 3, where only the dependent variable is changed. The key results regarding the impact of Hinku are shown in Table 4, while the full estimation results are shown in Tables B1 and B2 in Appendix B. Results in Table 4 show that Hinku has had a statistically significant impact on the emissions of electric heating and waste treatment. The impact on district heating, agriculture and industry were examined by deducting their emissions from the total Hinku emissions. This was done because there are municipalities without any district heating, agricultural and/or manufacturing

Table 4

Impact of Hinku membership on sector-specific and per capita emissions.

\begin{tabular}{lllll}
\hline Sector & $\begin{array}{l}\text { Hinku's } \\
\text { effect }\end{array}$ & $\begin{array}{l}\text { Standard } \\
\text { error }\end{array}$ & P-value & $\begin{array}{l}\text { Adjusted } \\
\mathrm{R}^{2}\end{array}$ \\
\hline Electric heating & $-3.03 \%$ & 0.015 & $0.043^{* *}$ & 0.794 \\
Oil heating & $1.14 \%$ & 0.015 & 0.451 & 0.855 \\
Consumption electricity & $-1.74 \%$ & 0.014 & 0.212 & 0.825 \\
Waste treatment & $-3.84 \%$ & 0.022 & $0.004^{* * *}$ & 0.698 \\
Road traffic & $-0.53 \%$ & 0.006 & 0.342 & 0.545 \\
Machinery & $-0.56 \%$ & 0.004 & 0.123 & 0.690 \\
Emissions without district & $-2.56 \%$ & 0.009 & $0.004^{* * *}$ & 0.738 \\
$\quad$ heating & & & & \\
$\quad$ Emissions without & $-2.00 \%$ & 0.009 & $0.019^{* *}$ & 0.793 \\
$\quad$ agriculture and & & & & \\
$\quad$ manufacturing & & & & $0.046^{* *}$ \\
$\quad$ Effort sharing sector & $-2.39 \%$ & 0.012 & 0.519 \\
Hinku emissions per capita & $-2.66 \%$ & 0.014 & $0.020^{* *}$ & 0.646 \\
\hline
\end{tabular}

Notes: Clustered standard errors are shown in parentheses. * $\mathrm{p}<0.1 ;{ }^{* *} \mathrm{p}<0.05$; $* * * \mathrm{p}<0.01$ 
emissions. In doing so, we avoid having a lot of zero values in the dependent variable. As the Hinku estimates decreased, it can be inferred that Hinku membership has also had an effect on district heating, agricultural and/or manufacturing emissions. When looking at the emissions of the whole effort sharing sector, our results show $(2.39 \%<3.1 \%)$ that the emissions of sectors excluded from the Hinku calculation cannot be influenced as strongly as the emissions of included sectors. Lastly, the connection between Hinku membership and per capita emissions is also statistically significant and negative $(-2.66 \%)$, but the impact is slightly lower than for total emissions $(-3.1 \%)$.

As we tackle questions of causality with the model and variable selections, certain issues need to be considered. It is possible that some Hinku municipalities would have carried out the same measures and investments regardless of joining the Hinku network. That is to say that there might exist a self-selection bias that would groundlessly emphasize the impact of Hinku on emissions. However, including the composition of political parties within the city councils into the analysis reduces this bias. Furthermore, any attitudes that remain fixed over the sample period are captured by the municipality-specific fixed effects.

Lastly, we conducted an analysis where additional lead-indicators were added for Hinku municipalities one and two years before the actual joining year. By doing so we can estimate any anticipatory effects from joining the network. Our results in Table C1 in Appendix C show that the lead-indicators are not statistically significant in explaining emissions. Thus, we can conclude that the municipalities joining Hinku are not always municipalities that foresee their emission development and do not base their decision to join on such expectations.

\subsection{Qualitative results}

The representatives of the interviewed municipalities regarded the Hinku network as effective in advancing local climate work. In $80 \%$ of the interviews it was stated that the network has in some form affected climate work in the municipality. The effects varied across municipalities. Among $60 \%$ of the municipalities it was mentioned that joining the network had affected the implementation of concrete climate measures, such as energy renovations in buildings or solar power investments, while in some municipalities the network was seen to have impacted the overall mindset within the municipality. In half of the interviews, the expert help received through the network was highlighted. In the following we elaborate on the factors of Hinku network membership that interviewees regarded as being the most effective in enhancing climate work in their municipalities (Fig. 3).

\subsubsection{Structuring climate work in municipalities}

As stipulated in the membership criteria, municipalities join the Hinku network by decision of the local council. According to the interviews, this public strategic commitment to specified emission reduction targets had been important. Often joining had been initiated by a key person in the municipality, an active council member from a political party (e.g. the Green League), or in some cases by a representative of SYKE. Joining the network had often happened as a natural continuation of climate or energy-related work already carried out in and around the municipality, but it may also have been seen as a new opening or an image-improving factor. Some neighbouring municipalities had decided to join together. In some cases, climate issues were brought into municipal strategies only upon joining the Hinku network.

Fulfilling the Hinku membership criteria serve as a basis for structuring climate work in the municipalities. The interviews revealed that these criteria are implemented to varying degrees. The main criteria were fairly well covered - over three quarters of the municipalities had both a contact person and some form of a working group that handles climate matters. The roles, titles and responsibilities of the appointed Hinku contact people varied, most of them working within the environmental or technical divisions, but the analysis found that their activity played an important role in advancing concrete action. Most municipalities had opted for a separate or joined working group dealing with sustainability, climate and/or energy matters, while a few included these matters on the agendas of existing higher-level working groups, such as the executive board group. In several cases, representatives of external parties such as schools, businesses, residents or youths had also been given a seat or had voluntarily gotten involved. Resource challenges were common among most municipalities, relating mostly to scarce human resources, time and finances. In spite of these challenges, our analysis found that implementing climate work within the municipal organisation was easier when it was legitimised vertically and shared horizontally.

\subsubsection{Providing expert support}

Analysis revealed that expert support had been utilised by at least half of the interviewed municipalities. Some municipalities had not yet asked for support and some hadn't needed it. The coordinator of the Hinku network was identified as a source of tailored tools, data and information, that most of the time are free for member municipalities to use. A key example - the nationwide local-level greenhouse gas inventory - was brought up in several interviews, functioning also as a baseline for further calculations of e.g. impact assessments and abatement potentials of climate work. Other expert support received from the network coordinator as mentioned by those interviewed included, for instance, support in communication planning and drafting of funding applications, especially for newer members, as well as initiating green public procurements, new projects or private sector involvement. Furthermore, participants had also found support from interactions with external expert organisations, which in many cases had been enabled by network membership.

\subsubsection{Offering peer support}

Alongside providing expert assistance, the network coordinator's role after establishing Hinku was recognized by interviewees as having facilitated systematic interaction and offered peer learning from

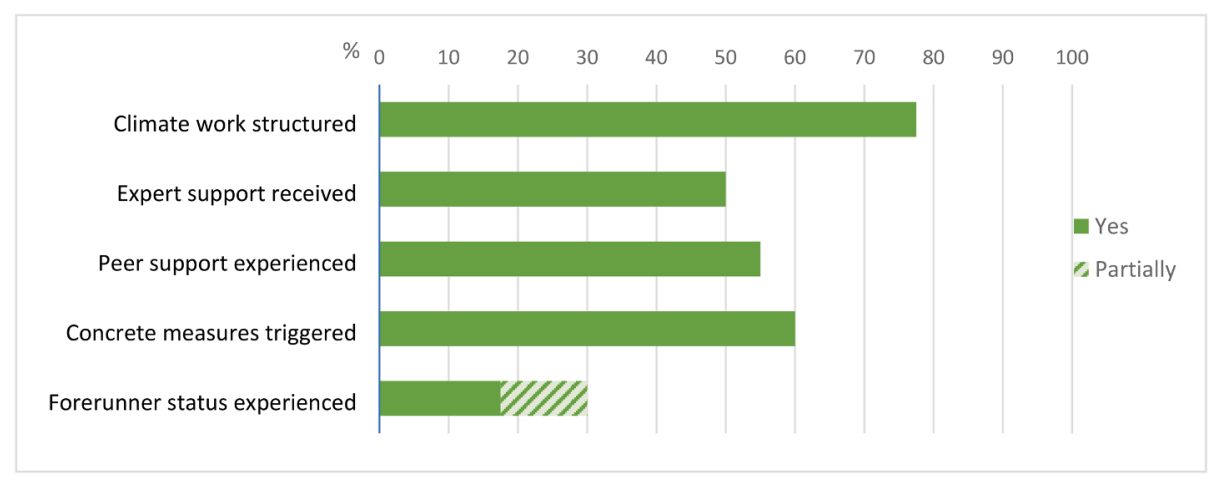

Fig. 3. Key factors effecting municipal climate work enhanced by Hinku network membership (Percentage of interviewed municipalities, $\mathrm{N}=40$ ). 
concrete actions between its members, especially through regional subprojects. Over half of the interviews revealed collaboration between peers connected to Hinku membership, with $25 \%$ mentioning networking as a significant benefit of having joined the network. In concrete terms, participants mentioned, for example, the biannual Hinku network days, where new ideas and best practices are shared. The network had also functioned as a means for key stakeholders and other expert organisations to connect with member municipalities, who are often regarded to a certain degree as forerunners. This had benefited member municipalities in the form of joint projects and procurements, for example, initiated by different actors. Regional collaboration was prevalent, especially in terms of collaboration between neighbouring municipalities with similarities in size or circumstance. Interviewees reported having received motivation and inspiration from the network, many paying particularly close attention to the activities and best practices of members that were regarded as most advanced in their climate work.

\subsubsection{Triggering concrete climate measures}

The interviewed municipalities reported a wide range and number of implemented emission reduction measures initiated after Hinku membership. Certain municipalities only named a few low-impact actions while others listed several investments, some with significant emission reduction potentials. According to the interviews, the municipalities' most important concrete actions included measures relating to heating and energy production (e.g. district heating, wind and solar instalments), energy efficiency in buildings and transport (e.g. electric vehicle charging infrastructure). In many municipalities concrete action had taken off slowly. While influencing firms or changing the behaviours of residents was found difficult, municipalities identified several avenues through which they can directly affect emissions outside the scope of the municipal organization. These include municipal owned energy and water companies, public procurement as well as land use planning and zoning regulations.

\subsubsection{Tracking progress}

In relation to the Hinku network's ambitious emission reduction targets, the interviewees showed some variance when asked whether they considered their municipalities to be forerunners. Nearly one third agreed to some extent, but many felt that no real action had yet been taken, that there had been little or no communication about the work being done, or that actions implemented due to Hinku had not been particularly special. Several interviewees, however, felt that their municipalities may yet become forerunners or that they are indeed forerunners, but only in certain sectors. Some municipalities were said to have committed to the targets having had no understanding of their required ambition or being under the assumption that state-level policies would automatically lead to sufficient emission reductions.3.2.6. Legitimizing local climate work

In addition to triggering concrete actions,joining Hinku had affected the general atmosphere and decision-making processes in some municipalities. Membership had even been used internally within the municipal organization by employees as grounds for allocating funds for often deprioritized climate related activities, appealing to the decision made by the local council upon joining the network to commit to reducing emissions. Municipalities recognized that Hinku membership had also provided legitimacy among citizens, with climate work being carried out in important channels of influence such as schools, daycares and other educational institutions. In cases where climate work had been met with opposition both within and outside of the municipal organisation, interviewees found it helpful to report on the economic perspectives and saving potentials of different concrete actions, supporting these claims with facts and figures. Media visibility of successful actions, active member municipalities and a growing network were recognized as being conducive to enhancing wide-spread climate work in the municipalities. Nevertheless, several municipalities struggled with private sector and public engagement.

\section{Discussion}

\subsection{Impacts of a climate network}

Greenhouse gas emission reduction targets set at the local level often surpass national ones in their level of ambition. Setting targets, however, is one thing, and achieving them is another. In many cases the local level is where the targets - be they global, national or regional - are put into practice. This is precisely why climate action on the local level is so crucial and why local governments are seeking for synergies and partnerships.

Climate networks are one form of intermediaries that are helping local governments in their endeavours. The beneficial role of intermediaries in municipal climate work has been noted in several studies (Stewart and Hyysalo, 2008; Kivimaa, 2014; Matschoss and Heiskanen, 2017; Saikku et al., 2017). However, the ability to quantify the impacts of climate actions or climate networks and other local level climate initiatives on the local scale has been missing due to a lack of appropriate metrics (Damsø et al., 2017; Boehnke et al., 2019). This is the research gap that our first research question concerning the measured impacts of climate network membership addresses. Recent work by Lounasheimo et al. (2020a) enabled us to utilise a suitable indicator, municipal greenhouse gas emissions, in identifying the impact of a climate network on municipalities in Finland. A similar approach to the evaluation of the effectiveness of local climate work could also be replicated elsewhere, provided that such a detailed metric can first be developed. In addition, reliable qualitative and quantitative evaluation requires long-term commitment alongside organized and welldocumented climate work.

According to our econometric analysis, emissions of Hinku network member municipalities are on average $3.1 \%$ lower than what they would be without Hinku membership, when other factors affecting emission levels have been taken into account. To improve causal inference, in addition to the specific time-varying factors, we controlled for any unobserved region-specific fixed effects, such as deeply rooted cultural factors, beliefs or attitudes that may partly determine municipal emissions. To tackle possible self-selection bias, we included the composition of political parties within the local councils into the analysis. The qualitative results also show that most of the municipalities have implemented additional emission reduction measures due to the existence of the Hinku network.

Our results also provide some evidence to support that climate work done as part of the Hinku network fulfils the network's aims of advancing cross-sectoral and systemic climate impact in municipalities. The systemic nature of climate action can be seen in the concrete measures implemented by member municipalities. The most highly valued ones included e.g. replacing fossil-based heating and energy production, investing in renewables through wind and solar instalments, or catalysing the electrification of the vehicle fleet by developing their charging infrastructure. Aside from triggering changes in the energy system, for example, the network generates systemic change by advocating for cross-sectorality in administrative climate work as well as for public engagement. Hinku climate work therefore likely passes through the whole municipality, as its overall impact on emissions results from development in multiple sectors. Although the identified impact is not huge, it is not negligible, given that the purpose of the network is to enhance local climate work by bringing municipalities and other stakeholders together. In other words, the results are largely positive, given that the operating costs of the network itself are quite modest.

From a modelling perspective, our study describes municipal emissions on a highly detailed intranational level, compared to previous econometric studies (see e.g. Huang et al., 2019; Hsu et al., 2020). Most of our results are in line with previous literature in relation to control variables (Franzen and Vogl, 2013; Minx et al., 2013; Zhou and Liu, 
2016). Political alignments revealed interesting results, and the emission reducing effect of a higher share of Green League members was also reflected in the interviews, according to which membership was often initiated by a member of the Green League party. The results also provided new evidence on the importance of municipalities' financial situations in the execution of climate work, which ought to be considered in central government budgeting.

On the other hand, in contrast to some of the previous literature (Wiedenhofer et al., 2017), our results show a statistically insignificant impact of urban form on emissions. Urban forms are classified based on certain area characteristics. For instance, the indicator used in this study is a combination of multiple factors related to population, jobs, service accessibility, building stock, road network and land usage (Helminen et al., 2020). That is, urban form correlates highly with the population size and average disposable income levels. Omitting other key determinants of emission formation may result in "mislabelling" certain impacts under urban form. Lastly, participation in the EEAM does not have a statistically significant effect on the total municipal emissions because its focus is only on the energy efficiency of the building stock of the municipal organisation itself.

Our quantitative results revealed that there is a statistically significant correlation between Hinku network membership and the level of municipal emissions, but how exactly does this occur? Our second research question aimed to answer this. Even though it was not possible to single out the exact role of the climate network as an intermediary, the interviews revealed what factors member municipalities regarded as effective in advancing local climate work. At best, network membership can provide a framework for structuring municipal climate work whereby it provides strategic vision translating to concrete actions with quantifiable emission reductions.

Successful climate networks offer tailored solutions (Rashidi and Patt, 2018). As members perceive that the Hinku network has provided expert support and translated climate targets into practical measures in the municipalities, the Hinku network can clearly be seen to function as a vertical intermediary (Gustafsson and Mignon, 2020). On the other hand, peer support in the form of shared experiences on climate experiments, examples of best practices or emotional support from colleagues and other municipalities speaks to its strong horizontal functions (Matschoss and Heiskanen, 2017). This was apparent especially regionally. Kivimaa et al. (2019) have argued that successful intermediaries function by networking, offering institutional support, building capacities and creating visions. The Hinku network clearly fulfils all these attributes.

What is interesting is how, in addition to the horizontal and vertical intermediary dimensions, the network manages to be a source of effects in itself. Hinku holds properties that go beyond the functions regarded as being integral to a successful intermediary. The network has managed to create an aura of legitimacy for the actors involved in municipal climate work. Municipal officials can, for instance, base their arguments for advancing climate measures on the Hinku status of the municipality. This is clearly supported by the Hinku requirement of strategic level commitment in offering leverage and guidelines, but the status can also build a positive responsibility for advancing climate work in the municipal actors' daily activities. The effectiveness of the network appears to stem from the combination of horizontal and vertical intermediation and the strong status of the network.

\subsection{Advancing local climate work via networks}

The idea of the Hinku network from the start has been to form a network of peers to encourage climate work on a local scale, in a costeffective and socially profitable way, in collaboration with local businesses and residents (Seppälä et al., 2011). The crucial role of municipalities in attaining the emissions targets, especially in the effort sharing sector, is recognised in national climate policy (MEAE, 2016). Overall, in the Nordic context, the relatively strong municipal autonomy further emphasizes the role of local level governments in putting the national and supra-national policy targets into practice (Keskitalo \& Liljenfeldt, 2012). Our study showed that for the most part, municipalities recognize their roles, opportunities and responsibilities in local climate work. Judging by the member municipalities' reduced emissions, the network has been successful.

However, in spite of the good efforts thus far, work remains to be done in terms of successfully facilitating local climate work, especially in terms of public engagement. Nagorny-Koring (2018) has suggested that best practice examples are useful in facilitating stakeholder mobilization through acceptance, while also activating political leadership. Similarly, Palermo et al. (2020) found that full engagement of stakeholders and citizens is required to effectively carry out actions and thus reduce emissions, also noting that smaller municipalities with fewer resources may need extra support in reaching their objectives. This is in line with the notions of tailored solutions by Rashidi and Patt (2018). However, tailored solutions require sufficient resources, especially as networks grow.

The Hinku network has experienced significant growth within recent years. From 5 municipalities in 2008, the network has expanded into 73 municipal members, several partner companies as well as five Hinku regions in 2020. All in all, these Hinku regions and municipalities cover $36 \%$ of the Finnish population, that is nearly 2 million people. Through its rapid expansion, the nature and focus of support offered by the network coordinator has evolved, shifting from direct, individualistic vertical support to a more horizontal and holistic approach. Obviously, this also means that expert solutions offered to municipalities are less tailored. However, regional actors have been harnessed to help lead climate action on the local level, partially counteracting the shift from tailored help into more aggregate vertical support. Repeating this study some years later will provide grounds for monitoring whether the network's continued expansion and shift has affected the climate work and emissions of both old members, as well as new ones. Furthermore, it will be possible to investigate the dynamics or lagged response of emission reductions as a result of Hinku membership when the time series gets longer.

It should be noted that simply joining a network and setting ambitious targets does not automatically lead to emission reductions, even if they have been occurring thus far. A recent study on the progress of certain EU Covenant of Mayors signatories found that cities on track to achieving their 2020 targets were in fact more likely to have lessambitious targets and higher baseline emissions, reflecting poorly on cities that had perhaps set unrealistically ambitions targets with incomplete action plans (Hsu et al., 2020). In light of our findings, we can also argue the opposite, considering the positive link between ambition level and actual emission reductions in the case of the Hinku network. Hinku's once highly ambitious emission reduction targets have remained unchanged for more than ten years, while the level of ambition of national policy has increased, the two converging. The network has still remained successful in boosting local climate action throughout the years - successes which may in turn reflect positively on the tightening of national level policies. In any case, ambitious local targets need to be aligned with systematic work and relevant actions. For this, actors need help in organising climate work and understanding the most efficient emission reduction measures, with incentives to execute them. When designed wisely, climate networks offer a worthwhile platform for this.

\section{Conclusion}

Climate networks can serve as a feasible platform for providing local governments with elements leading to systematic climate work. When the intermediation within these networks is designed and implemented carefully, climate networks can reduce local climate emissions, as our study shows. This requires network activities to stem from practical needs in local contexts. 
Our research is the first step towards measuring the quantifiable impacts of a climate network on greenhouse gas reductions on the local level. It is important to acknowledge that longer-term monitoring and evaluation of the emission dynamics is needed, as climate work calls for perseverance, while local governments face a budget constraint in making investments. Furthermore, as networks grow, the dynamics of co-operation and knowledge sharing may simultaneously be changing, which could have an evolving effect on the network's impact on local emissions.

The financial situation of local governments is one crucial factor affecting local emissions. Therefore, national and supranational policies need to ensure that municipalities are granted sufficient funding in their pursuit of carbon neutrality. Again, local governments need to be able to allocate scarce financial resources within their local contexts. At best, climate networks can offer the information, tools and capacities for optimising this allocation.

\section{CRediT authorship contribution statement}

Santtu Karhinen: Conceptualization of the quantitative study, Quantitative methodology, Formal Analysis relating to the econometric analysis, Validation, Writing - Original Draft. Juha Peltomaa: Conceptualization of the qualitative study, Qualitative methodology, Validation, Writing - Original Draft. Venla Riekkinen: Conceptualization of the qualitative study, Qualitative methodology, Investigation relating to the qualitative analysis, Data curation and formal analysis of qualitative data, Writing - Original Draft. Laura Saikku: Conceptualization of the whole study, Methodology, Investigation related to qualitative analysis, Writing - Original Draft, Supervision, Project administration, Funding acquisition.

\section{Declaration of Competing Interest}

The authors declare that they have no known competing financial interests or personal relationships that could have appeared to influence the work reported in this paper.

\section{Acknowledgements}

We gratefully acknowledge the two projects LIFE17 IPC/FI/000002 Life-IP CANEMURE-FINLAND - Towards Carbon Neutral Municipalities and Regions, and Towards EcoWelfare State: Orchestrating for Systemic Impact (ORSI) funded by the Strategic Research Council at the Academy of Finland (grant no. 327768) for their financial contributions to this study. We also thank each interviewee for their valuable time, as well as Teemu Helonheimo, Riikka Aro and Kati Pitkänen for conducting several interviews for the study. The authors thank Johannes Lounasheimo for discussions on details of municipal emissions calculation. We also thank three anonymous reviewers for their valuable comments on the paper.

\section{Appendix A. Supplementary data}

Supplementary data to this article can be found online at https://doi. org/10.1016/j.gloenvcha.2021.102225.

\section{References}

Aalto, J.A., Pirinen, P., Jylhä, K., 2016. New gridded daily climatology of Finland: permutation-based uncertainty estimates and temporal trends in climate. J. Geophys. Res. Atmos. 121, 3807-3823.

Ala-Mantila, S., Heinonen, J., Junnila, S., 2014. Relationship between urbanization, direct and indirect greenhouse gas emissions, and expenditures: a multivariate analysis. Ecol. Econ. 104, 129-139.

Association of Finnish Municipalities, 2019. Suomen kaupungit ja kunnat. Kaupunkien ja kuntien lukumäärät ja väestötiedot. Available at: https://www.kuntaliitto.fi/tilastot -ja-julkaisut/kaupunkien-ja-kuntien-lukumaarat-ja-vaestotiedot (Last accessed 23.9.2020)
Boehnke, R.F., Hoppe, T., Brezet, H., Blok, K., 2019. Good practices in local climate mitigation action by small and medium-sized cities; exploring meaning, implementation and linkage to actual lowering of carbon emissions in thirteen municipalities in The Netherlands. J. Cleaner Prod. 207, 630-644.

Damsø, T., Kjær, T., Christensen, T.B., 2017. Implementation of local climate action plans: Copenhagen - Towards a carbon-neutral capital. J. Cleaner Prod. 167, 406-415.

Dogan, E., Seker, F., 2016. Determinants of CO2 emissions in the European Union: The role of renewable and non-renewable energy. Renew. Energy 94, 429-439.

Dong, K., Dong, X., Dong, C., 2019. Determinants of the global and regional CO2 emissions: What causes what and where? Appl. Econ. 51, 5031-5044.

Eskander, S.M.S.U., Fankhauser, S., 2020. Reduction in greenhouse gas emissions from national climate legislation. Nat. Clim. Change 10, 750-756. https://doi.org/ 10.1038/s41558-020-0831-z.

Finnish Energy, 2020. Energy year 2020. Available at: https://energia.fi/files/4381/ Energy_Year 2019_-_Electricity.pdf (Last accessed 16.12.2020).

Franzen, A., Vogl, D., 2013. Two decades of measuring environmental attitudes: a comparative analysis of 33 countries. Global Environ. Change 23, 1001-1008.

Fuhr, H., Hickmann, T., Kern, K., 2018. The role of cities in multi-level climate governance: local climate policies and the $1.5 \mathrm{C}$ target. Curr. Opin. Environ. Sustain. $30,1-6$.

Garmann, S., 2014. Do government ideology and fragmentation matter for reducing CO2 emissions? Empirical evidence from OECD countries. Ecol. Econ. 105, 1-10.

GHG Protocol, 2014. Global Protocol for Community-Scale Greenhouse Gas Emission Inventories. An Accounting and Reporting Standard for Cities. Available at: ghg protocol.org/sites/default/files/standards/GHGP_GPC_0.pdf (Last accessed 14.9.2020).

Gordon, D.J., Johnson, C.A., 2018. City-networks, global climate governance, and the road to 1.5 C. Curr. Opin. Environ. Sustain. 30, 35-41.

Gustafsson, S., Mignon, I., 2020. Municipalities as intermediaries for the design and local implementation of climate visions. Eur. Plann. Stud. 28, 1161-1182.

Hausman, J.A., 1978. Specification tests in econometrics. Econometrica 46, 1251-1271.

Heikkinen, M., Ylä-Anttila, T., Juhola, S., 2019. Incremental, reformistic or transformational: what kind of change do C40 cities advocate to deal with climate change? J. Environ. Plann. Policy Manage. 21, 90-103.

Helminen, V., Nurmio, K. and Vesanen, S., 2020. Urban-rural classification. Reports of the Finnish Environment Institute 21/2020.

Hoppe, T., Van der Vegt, A. and Stegmaier, P., 2016. Presenting a Framework to Analyze Local Climate Policy and Action in Small and Medium-Sized Cities. Sustainability 8, 847. https://doi.org/10.3390/su8090847.

Hsieh, H.F., Shannon, S.E., 2005. Three approaches to qualitative content analysis. Qual. Health Res. 15 (9), 1277-1288.

Hsu, A., Tan, J., Ng, Y.M., Toh, W., Vanda, R., Goyal, N., 2020. Performance determinants show European cities are delivering on climate mitigation. Nat. Clim. Change. https://doi.org/10.1038/s41558-020-0879-9.

Huang, L., Kelly, S., Lv, K., Giurco, D., 2019. A systematic review of empirical methods for modelling sectoral carbon emissions in China. J. Cleaner Prod. 215, 1382-1401.

Keskitalo, E. C. H. and Liljenfeldt, J., 2012. Working with sustainability: Experiences of sustainability processes in Swedish municipalities. Natural Resources Forum 36/1, 16-27. Oxford, UK: Blackwell Publishing Ltd.

Kivimaa, P., 2014. Government-affiliated intermediary organisations as actors in systemlevel transitions. Res. Policy 43, 1370-1380.

Kivimaa, P., Hyysalo, S., Boon, W., Klerkx, L., Martiskainen, M., Schot, J., 2019. Passing the baton: How intermediaries advance sustainability transitions in different phases. Environ. Innovat. Soc. Trans. 31, 110-125.

Liu, Y., Zhou, Y., Wu, W., 2015. Assessing the impact of population, income and technology on energy consumption and industrial pollutant emissions in China. Appl. Energy 155, 904-917.

Lounasheimo, J., Karhinen, S., Grönroos, J., Savolainen, H., Forsberg, T., Munther, J. and Petäjä, J., 2020a. Calculating the greenhouse gas emissions of Finnish municipalities. Available at: https://hiilineutraalisuomi.fi/en-US/Emissions_and_in dicators/Calculation_principles (Last accessed 14.9.2020).

Lounasheimo, J., Karhinen, S., Grönroos, J., Savolainen, H., Forsberg, T., Munther, J., Petäjä, J. and Pesu, J., 2020b. The calculation of the greenhouse gas emissions of Finnish municipalities. Suomen ympäristökeskuksen raportteja 25/2020. ISBN 978952-11-5180-4. Available at: hdl.handle.net/10138/316216.

Lounasheimo, J., Karhinen, S., Grönroos, J., Savolainen, H., Forsberg, T., Munther, J., Petäjä, J. and Pesu, J., 2020c. Open database of the greenhouse gas emissions of Finnish municipalities. Available at: https://paastot.hiilineutraalisuomi.fi/\#en (Last accessed 14.9.2020).

Lukkarinen, J., Berg, A., Salo, M., Tainio, P., Alhola, K., Antikainen, R., 2018. An intermediary approach to technological innovation systems (TIS) - The case of the cleantech sector in Finland. Environ. Innovat. Soc. Trans. 26, 136-146.

Maddala, G.S., Wu, S., 1999. A comparative study of unit root tests with panel data and a new simple test. Oxford Bull. Econ. Stat. 61, 631-652.

Matschoss, K. and Heiskanen, E., 2017. Making it experimental in several ways: The work of intermediaries in raising the ambition level in local climate initiatives. Journal of Cleaner Production 169, 85-93.

MEAE (The Ministry of Economic Affairs and Employment), 2016. Government report on the National Energy and Climate Strategy for 2030. Available at: tem.fi/documents $/ 1410877 / 3570111 /$ Government + Report + on + the + National + Energy + and + Climat e+Strategy +for+2030/16a629e1-4ad6-4a58-96a6-347a7581177d/Government+ Report + on + the + National + Energy + and + Climate + Strategy + for +2030 .pdf.

Millard-Ball, A., 2012. Do city climate plans reduce emissions? J. Urban Econ. 71, 289-311. https://doi.org/10.1016/j.jue.2011.12.004. 
Minx, J., Baiocchi, G., Wiedmann, T., Barrett, J., Creutzig, F., Feng, K., Förster, M., Pichler, P.-P., Weisz, H., Hubacek, K., 2013. Carbon footprints of cities and other human settlements in the UK. Environ. Res. Lett. 8, 035039.

Nagorny-Koring, N.C., 2018. Leading the way with examples and ideas? Governing climate change in German municipalities through best practices. J. Environ. Plann. Policy Manage. 21, 46-60. https://doi.org/10.1080/1523908X.2018.1461083.

OSF, 2020a. Official Statistics of Finland: Energy supply and consumption [epublication]. ISSN=1799-7976. Helsinki: Statistics Finland. Available at: www.stat. fi/til/ehk/tau en.html (Last accessed 14.9.2020).

OSF, 2020b. Official Statistics of Finland: Population structure [e-publication]. ISSN=1797-5395. Helsinki: Statistics Finland [referred: 18.9.2020]. Available at: www.stat.fi/til/vaerak/index en.html (Last accessed 18.9.2020).

OSF, 2020c. Official Statistics of Finland: Employment [e-publication]. ISSN=23236825. Helsinki: Statistics Finland [referred: 18.9.2020]. Available at: www.stat.fi/t il/tyokay/index_en.html (Last accessed 18.9.2020).

OSF, 2020d. Official Statistics of Finland: Income distribution statistics [e-publication]. ISSN=1799-1331. Helsinki: Statistics Finland [referred: 18.9.2020]. Available at: www.stat.fi/til/tjt/index_en.html (Last accessed 18.9.2020).

OSF, 2020e. Official Statistics of Finland: Dwellings and housing conditions [epublication]. ISSN=1798-6761. Helsinki: Statistics Finland [referred: 18.9.2020]. Available at: www.stat.fi/til/asas/index_en.html (Last accessed 18.9.2020).

OSF, 2020f. Official Statistics of Finland: Municipal elections [e-publication]. ISSN=2323-1114. Helsinki: Statistics Finland [referred: 18.9.2020]. Available at: www.stat.fi/til/kvaa/index_en.html (Last accessed 18.9.2020).

OSF, 2020g. Official Statistics of Finland: Local government finances [e-publication]. ISSN=2343-4163. Helsinki: Statistics Finland [referred: 18.9.2020]. Available at: www.stat.fi/til/kta/index_en.html (Last accessed 18.9.2020).

OSF, 2020h. Official Statistics of Finland: Regional account [e-publication]. Helsinki: Statistics Finland [referred: 18.9.2020]. Available at: www.stat.fi/til/altp/index_en. html (Last accessed 18.9.2020).

OSF, 2020i. Official Statistics of Finland: Energy prices [e-publication]. ISSN=1799800X. Helsinki: Statistics Finland [referred: 18.9.2020]. Available at: www.stat.fi/ti l/ehi/index en.html (Last accessed 18.9.2020).

Ottelin, J., Ala-Mantila, S., Heinonen, J., Wiedmann, T., Clarke, J., Junnila, S., 2019. What can we learn from consumption-based carbon footprints at different spatial scales? Review of policy implications. Environ. Res. Lett. 14, 093001 https://doi. org/10.1088/1748-9326/ab2212.
Palermo, V., Bertoldi, P., Apostolou, M., Kona, A., Rivas, S., 2020. Assessment of climate change mitigation policies in 315 cities in the Covenant of Mayors initiative. Sustain. Cities Soc. 60, 102258 https://doi.org/10.1016/j.scs.2020.102258.

Rashidi, K., Patt, A., 2018. Subsistence over symbolism: the role of transnational municipal networks on cities' climate policy innovation and adoption. Mitig. Adapt. Strat. Glob. Change 23 (4), 507-523.

Reckien, D., Salvia, M., Heidrich, O., Church, J.M., Pietrapertosa, F., De GregorioHurtado, S., D’Alonzo, V., Foley, A., Simoes, S.G., Lorencová, E.K., Orru, H., Orru, K., Wejs, A., Flacke, J., Olazabal, M., Geneletti, D., Fleliu, E., Vasilie, S., Nador, C., Krook-Riekkola, A., Matosović, M., Fokaides, P.A., Ioannou, B.I., Flamos, A., Spyridaki, N.-A., Balzan, M.V., Fülöp, O., Paspaldzhiev, I., Grafakos, S., Dawson, R., 2018. How are cities planning to respond to climate change? Assessment of local climate plans from 885 cities in the EU-28. J. Cleaner Prod. 191, 207-219. https:// doi.org/10.1016/j.jclepro.2018.03.220.

Saikku, L., Tainio, P., Hildén, M., Antikainen, R., Leskinen, P., Koskela, S., 2017. Diffusion of solar electricity in the network of private actors as a strategic experiment to mitigate climate change. J. Cleaner Prod. 142, 2730-2740.

Salo, M., Nissinen, A., Nurmela, J., Mäenpää, I. and Savolainen, H., 2019. Tulokset: Erilaisten kotitalouksien hiilijalanjäljet. In: Nissinen, A. and Savolainen, H. (eds.) Julkisten hankintojen ja kotitalouksien kulutuksen hiilijalanjälki ja luonnonvarojen käyttö - ENVIMAT-mallinnuksen tuloksia. Suomen ympäristökeskuksen raportteja 15/2019, 39-48.

Seppälä, J., Toivonen, K. and Pietiläinen, O.-P., 2011. Kohti hiilineutraalia kuntaa. In: Niemelä, J., Furman, E., Halkka, A., Hallanaro, E.-L. and Sorvari, S. (eds.), Ihminen ja ympäristö, 418-427. Gaudeamus, Helsinki.

Seppälä, J., Saikku, L., Soimakallio, S., Lounasheimo, J., Regina, K., Ollikainen, M., 2019. Hiilineutraalius ilmastopolitiikassa - Valtio, alueet ja kunnat. Suomen ilmastopaneeli. Raportti 5a/2019.

Stewart, J., Hyysalo, S., 2008. Intermediaries, users and social learning in technological innovation. Int. J. Innovat. Manage. 12, 295-325.

Wang, S., Liu, X., 2017. China's city-level energy-related CO2 emissions: Spatiotemporal patterns and driving forces. Appl. Energy 200, 204-214.

Wiedenhofer, D., Guan, D., Liu, Z., Meng, J., Zhang, N., Wei, Y.-M., 2017. Unequal household carbon footprints in China. Nat. Clim. Change 7, 75-80.

Zhang, C., Lin, Y., 2012. Panel estimation for urbanization, energy consumption and CO2 emissions: a regional analysis in China. Energy Policy 49, 488-498.

Zhou, Y., Liu, Y., 2016. Does population have a larger impact on carbon dioxide emissions than income? Evidence from a cross-regional panel analysis in China. Appl. Energy 180, 800-809. 